\title{
THE TREATMENT OF HEMIPLEGIA IN CHILDREN
}

\author{
By SOPHIE LEVITT, B.Sc. (Physiotherapy) Rand.
}

$\mathbf{H}$ EMIPLEGIA is encountered by most physiotherapists, their approach differing according to the aetiology of the condition and to its clinical stage.

This article outlines the methods of treatment of hemiplegia in children as practised by the physiotherapy staff of the Johannesburg School and Treatment Centre for Cerebral Palsied Children. It is hoped that certain aspects of these treatment techniques may prove of value not only to those handling child hemiplegia, but also to those handling adults suffering from the condition.

\section{Principles of Treatment}

Parents are often heard commanding their young hemiplegics to "use your bad arm." Although perhaps objecting to the word "bad" many physiotherapists agree with this point of view in principle, in that they recommend intensive therapy of the affected side.

This approach has been discarded at the Johannesburg School and Treatment Centre, where it is believed that such emphasis of the hemiplegic side loses sight of the child as a whole, both physically and psychologically. The body's right and left sides do not function as independent units. HIRSCHBERG in their studies of gait in adult hemiplegics have recorded abnormal electromyographic patterns of the muscle work on the unaffected side. Although, this may be due to a mechanical disturbance rather than to any specific pathology of that side, the existence of a disturbance is clearly demonstrated. It is also interesting to note that HELLEBRANDT, in her work on "cross education," has shown that electromyographic activity takes place in the limb opposite to that carrying out a strong volitional movement. Arm amputees, particularly of the bilateral type, have found that the absence of a reciprocal arm swing interferes with the control of balance and of walking. The author has found it interesting to note that some of her cases of Parkinson's disease have remarked on the increased facility of walking once a reciprocal swing of the arms with the legs was achieved.

The affected side should, therefore, not be treated in isolation but as part of the patient's overall function. The hemiplegic child usually does not wish to make the effort to use a limb which does not move as easily as the others, and one agrees with ROBINAuLT that until the child reaches three years of age and prior to the need for skilled activities, he feels no loss in what he has never used. Then and later, he will devise ways of function, no matter how poorly, with no, or only minimal, use of the affected limb. Demands by therapists, teachers and parents that he should use the hemiplegic side will often result in a growing resistance to doing so. Some children will hide the affected hand by pulling down a jersey or shirt sleeve to cover it. The reaction of adults to hemiplegic limbs has been discussed by CRITCHLEY, the British neurologist, who has concerned himself more with the neurological denial of paralysed limbs than with the environmental causes of the reactions. This neurological phenomenon of "anosognosia" appears to be related to disturbed body image-a perceptual aberration. There are cases of "hemiplegia" in children which do not move their limbs because of astereognosis rather than because of spasticity or flaccidity, and a neurological report should be obtained to check this possibility. In any event, whatever the reason for lack of use of the affected side, constant demands made directly on that side, do not seem to the author to provide a solution. A 'holistic' evaluation of those cases where increased movement of the affected side has resulted from 'one-sided' physiotherapy must take into account the aggravation of other existing problems and/or the creation of new ones. Cerebral Palsy workers also suggest the possibility of difficulties related to handed- ness and that enthusiastic physiotherapy of a dominant hand may be associated with speech delay and defects, temper tantrums and even convulsions.

\section{Development of Function}

How, then, should the physiotherapist attempt to develop function in the affected side?

Physiotherapy must be planned to involve the use of the whole body, including the affected side, in enjoyable and interesting motor activities. HERN, of Queen's Square National Hospital for Nervous Diseases, London, has pointed out the additional necessity of "purposive movements" in her adult hemiplegics. Purposive, enjoyable and interesting movement in a child is best stimulated through play, his means of learning and self-expression.

\section{Aims of Treatment}

1. Prevention of deformities or contracture

2. Reciprocation.

3. Bilateral activity.

4. Balance training.

5. Postural training.

6. Education in walking.

Although these aspects of treatment will be discussed under the above headings, it will be obvious that these aims overlap and that they are all incorporated in the basic aim of developing function in the affected side.

\section{Prevention of deformities}

Deformities vary according to the individual case, the more common ones being shoulder abduction or semiabduction, elbow flexion or pronation, wrist palmarflexion, clenched wrist and thumb, hip and knee flexion and feet in either equinis, equino-varus or valgus. To prevent these deformities or postures becoming contractures, movements to counteract them are employed.

\section{(a) Shoulder:}

Children respond well to reaching overhead for large toys, hanging up toys or doll's clothes on a line, hitting balloons or pom-poms or bells suspended above the child's head. Exercises with a pole, soaping a mirror, the swinging of two light gym clubs and turning a skipping rope are useful for older children. Ball exercises are of particular value in all movements. Adaptions of the medicine ball exercises of Major Major have been made at the Johannesburg School and Treatment Centre with rewarding results. Stride standing, double handed throw and catch of a netball from overhead, from the chest from each side, from between legs, backwards, under each leg, bouncing from hand to hand and against a wall are all used. Different sized balls are recommended, the large beach ball being of special value with the very young child. Shoulder exercises such as the "windmill," sliding hands up a wall to touch marks or pictures at different levels, the powdered board, pushing away weighted toys on a slippery board and others known to physiotherapists, can supplement treatments.

\section{(b) Elbow}

Elbow movements usually emphasise extension and supination. Most of the exercises for shoulder elevation incorporate elbow extension. YAMSHON et al have pointed out that when the shoulder is flexed or abducted to 90 degrees, elbow extension is easiest for the hemiplegic. VERA FORD uses this optimal position and suggests giving the elbow motion resistance by grasping the patient's hand. Many clinicians, including YAMSHON, FORD, ROOD, PHELPS and FAY, have used the tonic neck reflexes described by neuro-physiologists. Tonic neck reflexes are associated with elbow extension, which may occur when the head is 
turned towards the hemiplegic arn and also when the head is extended. The latter is particularly noticed in four foot kneeling and, according to Ford, as the patient looks up when reaching overhead. The author's general impression is that tonic reflexes are not as prevalent in hemiplegics as in other cerebral palsy children.

Supination can be motivated by the child turning his hands to receive a toy, hold a ball or discover what his physiotherapist has "artistically" drawn on his palm. The children at the Johannesburg School and Treatment Centre have patronised the artistic efforts of their physiotherapists by carrying out various desired motions in order to see the drawings. The children's speech is also stimulated by this technique, and the skin-pencil or ballpoint drawings can be easily removed. Placing small variously shaped objects in the child's palm and encouraging him to first feel them and then to supinatc in order to see them is not only indirect movement exercise, but also uses visual images to counteract the astereognosis of hemiplegics, as discussed by TIZZARD, PAINE and CROTHERS. This supplcments the training of occupational therapists and educationalists. If assisted active supination is given, the grasp of the physiotherapis must be on the forearm and not twisting the hand.

\section{(c) Wrist and Hand:}

Wrist and hand are not dissociatcd for exercises. Holding the wall bars, parallel bars, the pole, various size balls, beanbags, the handles of a pram and examples of how the hand may be opened and grasp improved. Many activities in occupational therapy, the nursery school and kindergarten, such as water play with plastic toys, dishes, rags and rubber balls, dough modelling, fingerpainting, plasticene crafts, washing dolls' clothes, specific educational toys all develop the use of the hand. The activities must be skillfully chosen according to the individual case, as some children can carry out certain tasks satisfactorily with the unaffected hand alone. If this situation arises it is not, however, discouraged, as the child needs to establish his handedness and despite the many discussions on the subject the unaffected hand eventually becomes the leading hand Such activities are, thcrefore, permitted, whilst others are chosen to develop the hemiplegic hand as an assisting hand, passively, actively and also in bilateral or reciprocal action (discussed below) The emphasis on a particular kind of activity may vary at different stages of the child's development.

Exercises:

A standard elbow exercisc based on the natural activity of the young child is pronelying. hands placed flat at sides of shoulders - head raise progressed to pushing up on open hands, extending elbows. The head extension may stimulate the extensor reflex. Crawling with open hands is applicablc to some cases and most hemiplegics enjoy the "wheelbarrow," where they walk on their hands as the therapist holds the legs.

Action songs, used in association with the nursery and other teachers are strongly recommended. Examples are "Pat-a-cake," "We all clap hands together," "Fishes swim through water clear, birds fly through the air," "Rolly-poly," and many others. Many of the finger plays are valuable in their original or adapted versions, e.g. "Ten little gentlemen," "Six little Ducks," "The Baby"s Cradle," "Eensy Weensy Spider."

Leg movements are also based on counteracting the deformities and are predominantly included under the aitms of Reciprocation and Bilateral activity.

The limbs can also be exercised through the use of synkinetic movements, associated movements or mass movement patterns against resistance, as well as the use of other neurological reflexes, including "unlocking" reflexes. Foot dorsiflexion, for example, can be elicited by resisting hip and knee flexion (PHELP's Conditioned Motion); wrist extension by resisting elbow flexion and supination; wrist and
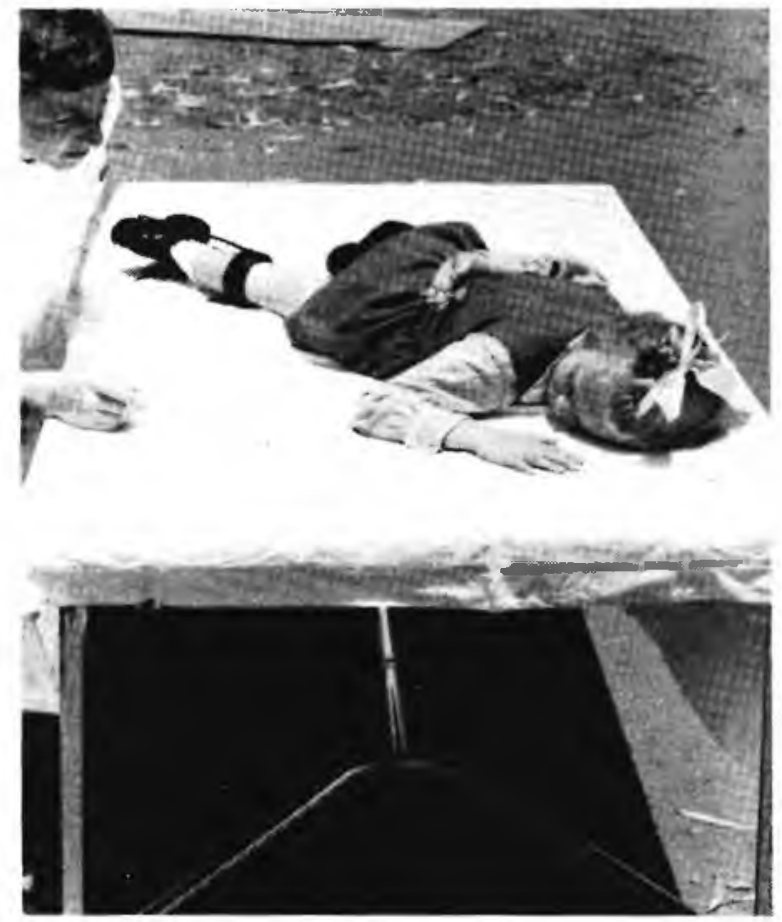

PATTERN MOVEMENTS-contra-lateral stage.

finger extension by stabilising shoulder abduction to 90 degrees, elbow flexion to 90 degrees and rorearm in supination. Resistance is given to elbow extension with resulting overflow to wrist. Added resistance to wrist results in extension. The more extensive patterns discussed by KABAT can be employed in certain cases. The "pattern movements" of TEMPLE FAY are discussed under Reciprocation.

\section{Contractures.}

Contractures are prevented by the corrective movements which are supplemented by proficiently applied passive manipulations, but not by forced movements.

In cases where contractures are developing, a nightsplint is used. The London Hospital type or the DennyBrowne adjustable sling for talipes has been found effective for the foot. Below the knee irons are occasionally used. Although raises on heels and/or soles are more common. There are those who recommend "full-length" leg braces in adults (WESSEROWITZ), but this is not recommended for children, and interferes with the teaching of a good walking pattern.

For tight deformities manipulation into below knee plasters for about six weeks has shown marked improvement. The plasters must be below knee and walking plasters, so that the physiotherapist can train gait in this corrected position.

\section{Reciprocation}

All simple movements of the limbs are given reciprocally (from side to side) and to a tune or rhythmic counting, in order to develop rhythm between both sides of the body. Toy pedal cars, tricycles, reciprocal pulley circuits and the arm reciprocator are used. The latter consists of the pedals of a small toy car. As the child turns the pedal with his hands, the car rolls up to him from the other end of the room. 
The Skis for quadriplegias are also used for the hemiplegia, as they involve opposite leg and arm motion, whilst feet are held fast and grasp is needed to hold the upright poles.

Climbing the jungle gym, or wall bars, invloves many desired movements as well as reciprocation.

At the Johannesburg School and Treatment Centre, TEMPLE FAY's pattern movements, based on primitive reflex patterns, constitute an important part of the treatment, as they emphasise motion of the whole body, develop reciprocation and counteract 'butterfly,' or straying, attention. Rhythm is stressed and it has been noted that if the arm is brought behind the back instead of to the side an 'unlocking' or relaxing, reflex of the thumb may occur.

Swimming is an activity where a stimulation of reciprocal motion in arms and legs has been observed.

\section{Bilateral Activity}

The majority of the movements already described under aims 1 . and 2. above are also carried out bilaterally. The amount of bilateral hand activity may vary with each child and consideration must be given, in conjunction with the occupational therapist, to the possibility of submerging the dominant hand. Further examples of bilateral exercises include:

(i) Hand clapping exercises-overhead, front and back, etc.

(ii) Jumping exercises, such as : feet astride and together, bob-jump, jumping over toys placed on floor, bunny-jump.

(iii) Hitting a ball with a cricket bat held in both hands.

(iv) Skipping.

(v) Heels raise, double knee bend and stretch.

(vi) Double arm hanging-2 leg open and close.

2 knee bend and stretch.

(vii) "Star exercises" or Double arm and leg abduction and adduction simultaneously-in lying, hanging or holding the wall bars with one side.

(viii) Prone or lying on form or inclined board-grasp sides of board, pulling up to opposite end of board.

\section{Balance}

It has been observed that standing balance on the affected leg is deficient and thus balance training has been introduced into the treatment programmes of the hemiplegic. Balance positions of half kneeling, half kneel with leg stretched sideways, forwards or backwards, kneeling, half standing, step standing, foot support standing, etc. are used, and other balance exercises given.

\section{Posture Training}

At the Johannesburg School and Treatment Centre observations are at present being made of the variation of hip and shoulder levels, scolioses, the appearance of kyphoses and lordoses and limb postures. Postural exercises and training are based on the individual postural examination of each case. In those cases where the scoliosis is compensatory for a marked shortening in an underdeveloped leg, exercises are not designed to counteract the scoliosis, but only to mobilise the spine and to strengthen the trunk.

\section{Education in Walking}

The walking pattern in children is not often the same as that seen in adult hemiolegics. Circumduction is a rare problem compared to hip rotation and foot deformities. The exercises discussed above are related to the walking pattern. The stress in the education in walking as in all movement in cerebral palsied children-is based on the capabilities of the child. TEMPLE FAY's pattern of walking i.e. the exaggerated normal walk, is particularly useful for the hemiplegic. It involves the rhythmic co-ordinated action of the affected and unaffected sides.

Walking in a placement ladder, in the eversion board, stepping over toys on the floor, stepping on the balance bar and going up steps all counteract the 'drag' of the hemiplegic foot and improve foot placement.

Walking up an inclined plane promotes dorsiflexion and also diminishes the "scraping' of the foot. 'Walkers' are not used with these children, as they are considered to be too artificial. Instead, the children are encouraged to acquire ambulation at their own natural rate.

\section{Concept of Treatment}

There is, in some quarters, an unfortunate tendency to consider the treatment of the hemiplegic child only in terms of his physical handicap. If this handicap is mild one sometimes hears the suggestion that the child should go to a normal school and attend an Outpatient's Department at a hospital or at a cerebral palsy school. Provided that such a child is observed, over a period of time, by a properly qualified cerebral palsy team, i.e. one including specialised medical, educational and psychological personnel, such an arrangement may prove satisfactory. It is, of course, clear that such an overall assessment can only be effected at an institution which integrates education with treatment.

Physiotherapists must obviously take cognizance of factors other than the motor handicap, thus gaining an integrated picture of their patients. They must be aware of the possible defects in speech, behaviour, learning and perception (the interpretation of sensory stimulii such as vision, hearing and touch) in otherwise intelligent hemiplegias, and understand what part the physiotherapist should play in handling these difficulties, and possibly consider what influence these defects may have on motion. For example, BRUELL et al posit a "disturbance of perception of verticality in Hemiplegias which could influence walking in dimly lit surroundings. SHONTZ has discussed disabilities in body concept, TEUBER and his staff have made worthwhile contributions to the understanding of various perception problems of the brain-injured adult, whilst STRAUSS and LEHTINEN have studied the perception, behaviour and learning difficulties of the brain injured child.

The possible existence of the various defects mentioned above underlines the necessity of integrating physiotherapy with education, and psychology, as well as with the other therapies with which it so often overlaps.

\section{SUMMARY}

The treatment of hemiplegia in children, as developed at the Johannesburg School and Treatment Centre for Cerebral Palsied Children, has been outlined, and some comparisons made with the treatment of hemiplegia in adults.

The importance of treating the affected side as part of the patient's overall motor functioning, as well as the importance of attempting to co-ordinate physiotherapy with education, psychology and other therapies, has been stressed.

\section{REFERENCES}

1. Bruell et al. Disturbance of Perception of Verticality in Patients with Hemiplegia. Arch. Phys. Med. Vol. 37. No. 7. (Nov, 1956).

2. Critchley Macdonald: Personification of Paralysed Limbs in Hemiplegia. Brit. M. J. July 30, 1955.

3. FAY TEMPLE: Personal Communication 1954 (1954) Spastics' FaY TEMPLE: Personal CO Vol. 3 , No. 3 .

4. Ford VERA: Use of Tonic Neck refiexes and Positioning in Upper Extremity Exercises for Early Cerebral Vascular Hemiplegia. Phys. Th. Rev. Vol, 32: No. 9, Sept. 1942.

5. HellebrandT. Cross-education. J. of Applied Physiology. 4. Aug. 1951.

HellebrandT. Cross-education. Arch. of Phys. Med. Vol. XXVIII. Feb. 1947.

6. Hern, K. M.: Re-education for Neurological Cases. PhysiotherapVol. 36: No. 2. Feb. 1950.

7. HiRsChBerg AND NATHANSON: E.M.G. recording of Muscular Activity in Normal and Spastic Gaits. Arch. Phys. Med. Vol. XXLLL. No. 4, April 1952.

8. KabaT: Principles of Neuromuscular Re-education. Phys. Th. Rev May-june 1948 .

KABAT: Specialised Neuromuscular Re-education. Phys. Th. Rev. Feb. 1952.

9. Phelps, W. M.: Personal Communication and Study Course for Diploma in Cerebral Palsy, Baltimore, U.S.A. 1953.

10. ROOD: M.O.T. in the Treatment of the Cerebral Paisied. Phys. Th. Rev. Feb. 1952. 


\section{CHANGE OF ADDRESS}

Mr. K. Branson, 88, Denys Reitz Road, Roosevelt Park, Johannesburg.

Miss A. Mayor-Davies, Guy's Hospital, London.

Mrs. K. Roodt (neé Z. v.d. Spuy), 113, Muldersdrift

Road, Roosevelt Park, Johannesburg.

Miss H. M. Smith, c/r. Main and Worcester Roads,

Sea Point, Cape Town.

Mrs. J. Nicol (neé J. Feyder), Doctors Residence, Esselen Street, Johannesburg.

Mrs. C. Matejka (neé C. v.d. Spuy), 44, Servern Court,

c/r. Claim and Hancock Street, Johannesburg.

Mrs. Halpern, 91 North Avenue, Observatory Curve, Johannesburg.

Mrs. M. Goodman, 16 Victoria Avenue, Sandringham, Johannesburg.

\section{NEW MEMBERS}

Miss B. van Graan, 148 Dey Street, Brooklyn Pretoria, N. Tvl. Branch.

Miss M. Lemmer, 55, Brook St., Brooklyn ,Pretoria.

N. Tvl. Branch.

Miss J. de W. Stassen, Pretoria Hotel, Schoeman Street, Pretoria, N. Tvl. Branch.

Miss L. van Wyk, 157 Venter Street, Capital Park, Pretoria N. Tvl. Branch.

\section{BRANCH NEWS}

\section{SOUTHERN TRANSVAAL BRANCH NEWS.}

We would like to congratulate the student members who obtained their B.Sc. Physiotherapy Degree at the end of 1956. Application for full membership of the South African Society of Physiotherapy from these members has been disappointing. Forms are obtainable from:-

MRS. R. BLIEDEN, 706 Tafelberg, Esselen Street, Johannesburg.

Eleven student members have joined the Branch. We would like to welcome them and hope to see them at our meetings and lectures.

\section{WESTERN PROVINCE BRANCH -}

The General Meeting was held on January 30th at the Cerebral Palsy School, Rondebosch. Eighteen branch members were present and welcomed Mr. Moth from Princess Alice Home and Miss Ursula Scott from StokeMandeville and now at the Conradie Hospital.

\section{Shortage of Physiotherapists}

Because of the emergency caused by the current polio outbreak it was decided to form a "pool" of Physiotherapists from which Hospitals can draw when necessary. Several members have volunteered for part-time services.

New Office Bearers

Chairman: Mr. Schermbruker.

Vice-Chairman' Mr. Tom Hart.

Secretary: Mr. K. Nicol.

Treasurer: Mr. B. Woodgate.

Committee Members: Miss U. Scott, Mrs. Alais, Mr. Oliver, Mrs. E. Myer.

Co-opted Members: Miss S. Sutherland.

Forthcoming Meeting

Discussion on Polio:-Guest Speakers: Mr. McMurray and Mr. Swartz at the Red Cross Hospital Lecture Theatre, Rondebosch.

References-Continued from page 6

11. Shontz, F. C.: Body Concept Distrubance. J. of Clin. Psych. 12: 3 July, 1956.

12. RobinaulT: Occupational Therapy Technics for Pre-school Hemiplegic: Am. J. of O.T. Vol. VIII. No. 5. Sept.-Oct. 1953.

13. Strauss and LeHTiner (1947): Psychopathology of the BrainInjured Child. Grone \& Stratton Inc., New York. Edit. 1950.

I3. Teuber Hans lukas: Personal Communication 1954 1955. TEUBER AND MishKIN: Judgment of Visual and Postural Vertical after and Brain Injury. J. of Psychology, 1954, 38: 161-175.

Teuber, Price and KRueger: Tactile Extinction in Parietal lobe TEUBER, Price and KRUEGer: Tactile Extinction in
Neoplasm. J. of Psychology, 1954. 38: 191-202.

Teuber, Semmes, Weinstein, Ghent: Performance of complex Tactual task after Brain Injury in Man. Am. J. of Psych. July 1954.

14. Tizzard, Paine and Crothers.: Disturbances of Sensation in Children with Hemiplegia. J. of Am. Med. Assoc. 12: July 1954. Vol. 155.

15. VON WERSSOWETZ: Supporter's Appliances for Ambulatory Rehabilitation of Hemiplegics. Journal Phys. Therapy Review. Vol 31. No. 1. Jan. 1951.

16. Yamshon, WATCHEK, Covalt: The Tonic Neck Reflex in the Hemiplegic: an objective study of its Therapeutic Implications. Arch. of Phys. Med. 30: 706-711, Nov. 1949.

YAMShoN, Covalt, Nowicki: Physiological Acd. to the Functional Training of the Hemiplegic A.m. Am. J. of O.T. Nov.Dec. 1949.

\section{ACKNOWLEDGEMENT}

Acknowledgement is made to Mr. J. Halpern for constructive criticism of this article.

1. The present physiotherapy staff of the Johannesburg School and Treatment Centre for Cerebral Palsied Children consists ofThe Author and Mesdames: M. Bloch

B. A. Bower

C. Chasan

2. In accordance with the new ruling of the Management Committee of the Johannesburg School and Treatment Centre for Cerebral Palsied Children, the Committee's permission to publish this article has been obtained.

\section{DIATHIERMY MACHINES}

In October, Mr. Kelly and I had an interview with Post Office officials. The points raised were:-

(1) With what do our diathermy machines interfere?

(2) Can the machines be adapted?

(3) Will we be compensated for machines which have to be scrapped?

The answers we got were:-

(1) Our diathermy machines are most likely to interfere with radio and telecommunications.

(2) The Post Office representatives thought that the machines could be converted to the new frequencies, but suggested that we consult Mr. Joubert of the Bureau of Standards.

(3) The Post Office would definitely not pay compensation. But (according to the Post Office) the Department of Public Health could, if necessary, arrange loans for our members. I have contacted the Department of Public Health and they seem rather doubtful about this matter of loans.

We met Mr. Joubert in January and discussed the matter of conversion of the old diathermy machines to the new frequencies. He had gone into the matter thoroughly, and was of the opinion that it would not be wotrh while having our machines converted. It would probably be quite a costly business, and it is doubtful whether it would be satisfactory. The frequency would have to be adjusted in such a way that it would be constant under all conditionsnamely, temperature, humidity, load, change of valve, etc.

If anyone decided to have a diathermy machine adapted, Mr. Joubert suggested that whoever did the conversion, should be made to guarantee, in writing, that the work done meets with the requirements of the Post Office. This will prevent exploitation by unscrupulous persons.

Meantime, the old machines may still be used after December 31st, 1957, providing that there are no complaints about interference from them. Should there be any complaints of interference, the Post Office would have to satisfay the owner of the machine that it was his/her particular machine which was causing the interference.

I feel that no more can be done in the matter. We must just hope that we have no complaints about interference from our diathermy machines for as long as they last.

M. EMSLIE. 